\title{
COST CONTROL MODELING FOR REAL ESTATE PROJECTS IN EGYPT
}

\author{
Mennatallah M. Kamal ${ }^{1}$, Ayman H. Nassar ${ }^{2}$ \\ ${ }^{1}$ B.S.C of Civil Engineering, The German University in Cairo, Cairo, Egypt \\ ${ }^{2}$ Lecturer of Construction and Project Management, German University in Cairo, Cairo, Egypt
}

\begin{abstract}
Cost control is a comprehensive project through the real estate developing process, it is the center of gravity of real estate developing companies work. This paper takes the cost control and the management of real estate project as the object in research, and analyzes and studies relevant issues. By analyzing the cost structure of real estate construction, this paper identifies problems in cost control and management of real estate construction at present. Besides, this paper puts forward measures for cost control and management of real estate construction, with the hope of offering useful ideas for this issue.
\end{abstract}

Keywords:- Cost Control, Real Estate Projects, Cost Management.

\section{INTRODUCTION}

Cost has its proven importance as the prime factor for project success. Most of the significant factors affecting project costs are qualitative such as client priority on construction time, contractor's planning capability, procurement methods and market conditions including the level of construction activity (Elchaig, Boussabinaine A., \& Ballal T., 2005). A project otherwise completed may not be regarded as a successful endeavor until and unless it satisfies the cost limitations applied to it.

In spite of its proven importance it is not uncommon to see a construction project failing to achieve its goal within the specified cost. Cost overrun is a very frequent phenomenon and is almost associated with all projects of construction industry. Cost overrun can be simply defined as when the final cost of the project exceeds the original estimates. According to one very comprehensive research made on cost overruns in global construction, it was found that 9 out of 10 projects had overrun. It is believed that construction projects experience an increase in cost of about $33 \%$ on average. (Hartley \& Okamoto, S., 1997)

Project planning cannot be completed satisfactorily by only planning and scheduling. Project controlling which consists of project monitoring and updating, is the other important stage to be carried out to accommodate the dynamic nature of construction work. Without a proper control, even a wellplanned and scheduled construction system can lead to problems, delays and cost overruns. In general most (if not all) construction projects experience time delays and cost overruns during their implementation phase. Cost overruns are considered as one of the most critical issues during the execution of construction projects. (Premalal, Mudalige, \& Malkanthi, 2016)Lack of ability to prevent cost overruns or to control construction costs causes many construction companies to fail.
To control the cost attention must be paid to the three stages of the cost management processes "CMP" cost estimating, cost budgeting , cost control

Cost Estimating: A prediction of quantities, cost, and/or price of resources required by the scope of an asset investment option, activity, or project.

Cost Budgeting: Cost budgeting involves allocating the overall cost estimates to individual work items in order to establish a cost baseline for measuring project performance

Cost Control: Cost control is concerned with:

- Influencing the factors which create changes to the cost baseline to ensure that changes are beneficial.

- Determining that the cost baseline has changed.

- Managing the actual changes when and as they occur.

Through all the 107 research papers and journal articles studied, 97 factors causing cost overrun were obtained which was later simplified into 41 factors. This research attempts to identify the major factors of cost overrun in construction sector of Egypt and can serve as the way forward for future work in coping with these overruns.

\section{METHODOLOGY}

\subsection{Problems Categorization}

We have gathered 41 different problems that cause project cost overrun classified into 8 different categories as shown below in table 1 . 
Table 1

\begin{tabular}{|c|c|}
\hline Category & Determinants \\
\hline $\begin{array}{lr}\text { Design } & \text { and } \\
\text { documentation } & \text { related } \\
\text { factors } & \end{array}$ & $\begin{array}{l}\text { Factors related to quality of } \\
\text { project, delays related to } \\
\text { problems with project design } \\
\text { and documentation work. }\end{array}$ \\
\hline $\begin{array}{lr}\text { Contractor's } & \text { site } \\
\text { management } & \text { related } \\
\text { factors } & \\
\end{array}$ & $\begin{array}{l}\text { Factors related to site } \\
\text { management and scheduling } \\
\text { related factors. }\end{array}$ \\
\hline $\begin{array}{l}\text { Financial management } \\
\text { related factors }\end{array}$ & $\begin{array}{l}\text { Factors related to unreasonable } \\
\text { constraints to owner, funding } \\
\text { shortage. }\end{array}$ \\
\hline $\begin{array}{lr}\text { Information } & \text { and } \\
\text { communication } & \\
\text { technology } & \text { related } \\
\text { Factors } & \\
\end{array}$ & $\begin{array}{l}\text { Factors related } r \\
\text { communication } \\
\text { project members. }\end{array}$ \\
\hline $\begin{array}{l}\text { labor management } \\
\text { related factors }\end{array}$ & $\begin{array}{l}\text { Factors related to performance } \\
\text { skills of the workforce, job } \\
\text { instructions, constructions, } \\
\text { methods, tools and equipment. }\end{array}$ \\
\hline $\begin{array}{l}\text { Material and machinery } \\
\text { related factors }\end{array}$ & $\begin{array}{l}\text { Factors related to shortages of } \\
\text { materials, fluctuations in the } \\
\text { price of materials, lack of } \\
\text { assessment in relation to } \\
\text { location and local suppliers. }\end{array}$ \\
\hline $\begin{array}{l}\text { Project management and } \\
\text { contract administration } \\
\text { related factors }\end{array}$ & $\begin{array}{l}\text { Factors related to project } \\
\text { management. }\end{array}$ \\
\hline $\begin{array}{l}\text { Environment and } \\
\text { economy }\end{array}$ & $\begin{array}{l}\text { Factors related to social, } \\
\text { environmental and economic } \\
\text { effects. }\end{array}$ \\
\hline
\end{tabular}

(Problem categorization table)

\subsection{Solutions Categorization}

And from the interviews, we gathered 32 solution to minimize the whole project cost overrun which are classified into 5 categories as shown below in Table 2 .

\section{Table 2}

\begin{tabular}{|l|l|}
\hline Category & Determinants \\
\hline $\begin{array}{l}\text { Financing issues } \\
\text { control /project cost } \\
\text { management }\end{array}$ & $\begin{array}{l}\text { Factors related to financing the } \\
\text { project and cost management. }\end{array}$ \\
\hline $\begin{array}{l}\text { Monitor methods for } \\
\text { the project }\end{array}$ & $\begin{array}{l}\text { Factors related to monitoring the } \\
\text { project performance in terms of cost } \\
\text { and schedule. }\end{array}$ \\
\hline Change control & $\begin{array}{l}\text { Factors related to controlling any } \\
\text { change that may arouse during the } \\
\text { project. }\end{array}$ \\
\hline Risk management & $\begin{array}{l}\text { Factors related to identifying and } \\
\text { controlling the threats that may } \\
\text { face/is facing the project. }\end{array}$ \\
\hline Project management & $\begin{array}{l}\text { Factors related to schedule, site, and } \\
\text { technical office management. }\end{array}$ \\
\hline
\end{tabular}

(Solutions categorization table)

\subsection{Research Parts}

This research is carried out in three stages. First part is data collection which was done through readings of research papers, journal articles, interviews and two questionnaires. Second part is data analysis of the results we got from the final questionnaire and using crystal ball to get high certainty of the results we got. The third part was the model simulation.

The first questionnaire is a pilot questionnaire which was composed mainly of one part in which the interviewee was asked to rate the factors causing cost overrun, it was done to know the average results of the respondents and was followed by interviews with experts to gather some solutions to minimize the cost overrun.

The final questionnaire is composed mainly of two parts and so does the analysis. First part of the questionnaire is the problems part (how will each problem affect the whole project cost. This part is composed of two parts which is the probability and severity of each problem and each is scaled from 1 to 5 as 5 is very important or very severe or has high probability to happen. The second part of the questionnaire is the solutions part (how much will each solution help to minimize the whole project cost.

The second part was done after the analysis, the crystal ball was used to get high certainty of the results we got from the analysis we got from the final questionnaire. Beta pert distribution was used for each problem and for every solution for each problem. Then, the analysis was done again.

The Third part was the model simulation .The model was designed to be a guide for anyone involved in the construction field, first of all, the user will choose the category of the problem he is facing, then, the model will present the problems that the user may face during the project, it will present also the percentage of each problem affecting the project, this will show us the percentage of overrun each problem may cause. The model will show the user the solution(s) for each problem, this will make the user know the percentage each solution can help to minimize the cost overrun of the project. The model was made using visual basic excel sheet, it was designed to be user friendly, it will only take few seconds from the user to know the solution(s) of his problem.

\section{DATA ANALYSIS AND RESULTS}

Initially, 107 studies were obtained, Factors affecting cost overrun were obtained. 97 factors were identified and we had 3 interviews with 3 experts and they simplified these 97 factors into 41 factor according to their importance which were stratified to homogenize the best grouping factors within the 8 categories.

Based on our readings a pilot questionnaire was designed seeking to obtain evidences in relation to the factors and the level of importance, it was composed mainly of 1 part in 
which the interviewee was asked to rate the factors causing cost overrun in term of their probability to happen and their severity if it happened in a scale varied from " 1 " to " 5 " where " 5 is very important and 1 is not important.

The pilot questionnaire was followed by 12 interviews to gather solutions for the factors causing cost overrun which was categorized into 5 categories where this lead us to the final questionnaire.

The final questionnaire was composed mainly of two parts, in part 1 the interviewee was asked to rate the factors causing cost overrun in term of their probability to happen and their severity if it happened in a scale varied from " 1 " to " 5 " where " 5 is very important and 1 is not important.

The analysis for part 1 (Impact of each factor) was then calculated by simple calculation:

$$
\operatorname{Impact}=\Sigma(\mathbf{P} * \mathbf{S}) / \mathbf{n}
$$

Where: $\mathrm{P}$ is the probability of this factor to cost overrun (out of $100 \%)$.

$\mathrm{S}$ is the severity of this factor if happened (out of 100\%).
$\mathrm{N}$ is the no. of respondents which are 50 for the pilot questionnaire and 150 for the final questionnaire.

The analysis for part 2 (the solution(s) concerning each problem) are out of 100 , so the analysis of each solution was calculated by this simple equation.

Impact $=(\mathbf{N} * 100) / S$

Where $\mathrm{N}$ is the number we got from the analysis out of 100 . $\mathrm{S}$ is summation of the analysis out of 100 (concerning each problem).

Part of the analysis depends on the number of the questionnaire respondents so, by comparing the results of the common part of the pilot questionnaire and the final questionnaire (problems causing cost overrun), we have seen a huge difference in the percentages of the factors that cause cost overrun. So, we searched for a method to give higher certainty level, so, crystal ball was used, Beta pert distribution was used with inputs which are minimum value, likeliest value and maximum value, we have seen that the factor percentage doesn't change after 2000 trial, this means 2000 or more respondents for each factor will give the same percentage, we have made $75 \%$ certainty level.

As we have 8 categories causing cost overrun these were their top 8 factors:

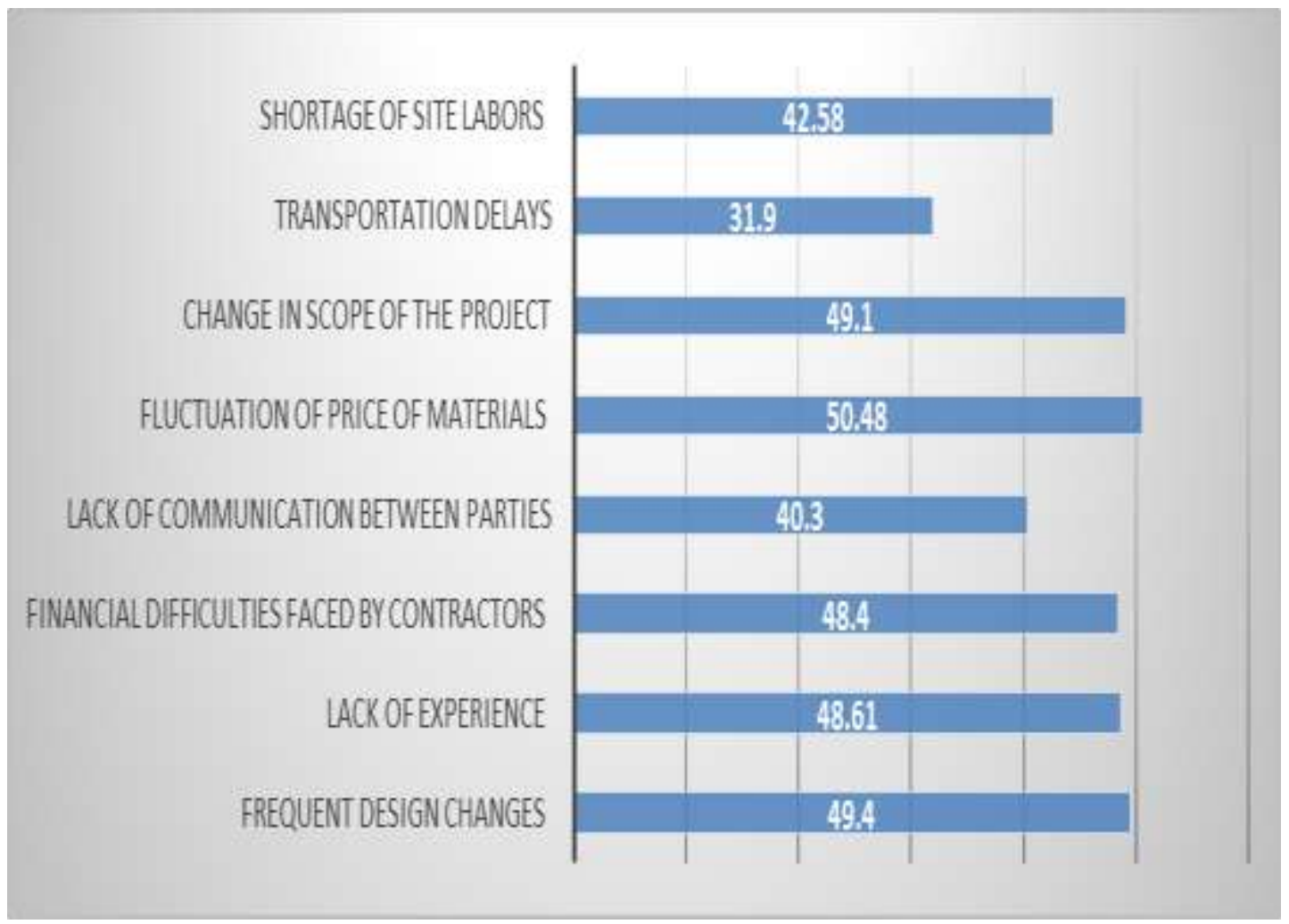


And these are the solutions for the top 3 factors causing cost overrun:

For:Frequent design changes

$17 \% \quad 16 \%$
$17 \%$
hire experienced managers $17 \%$
hire experienced engineers $16 \%$
control the design changes
Proper project planning and scheduling
Setting and Releasing Cost Contingencies
Build penalties into the process (to any delay or any change)

For :Change in scope of the project

$12 \% \quad 12 \%$

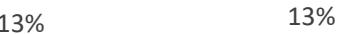

$12 \%$

$12 \%$

$13 \% \quad 13 \%$

Build penalties into the process ( to any delay or any change )

Control the design changes

Effective strategic planning

Proper project planning and scheduling

Effective site management and supervision

Coordination between all parties, frequent meetings

Proper emphasis on past experience

Perform a preconstruction planning of project tasks and resources needs 


\section{SOFTWARE DEVELOPMENT}

It was very hard for the user to search for the results manually this lead us to facilitate the process for the user so we thought to develop a software. The model was made using visual basic excel sheet. The model is user friendly and can be edited easily for any future modification. And the below figures will illustrate the steps from initiating the model till knowing the solution percentages. And these are randomly taken shots from the model.
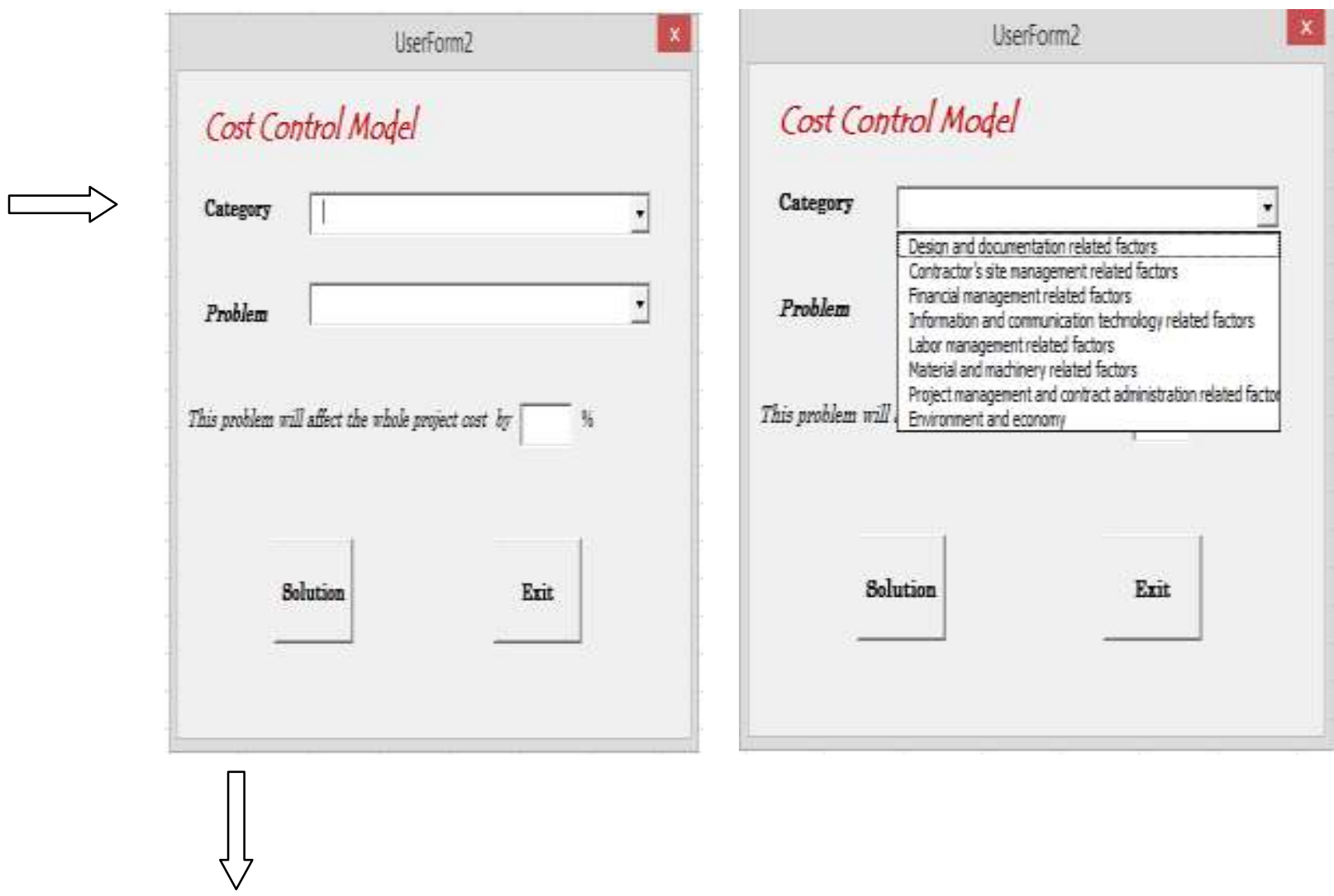


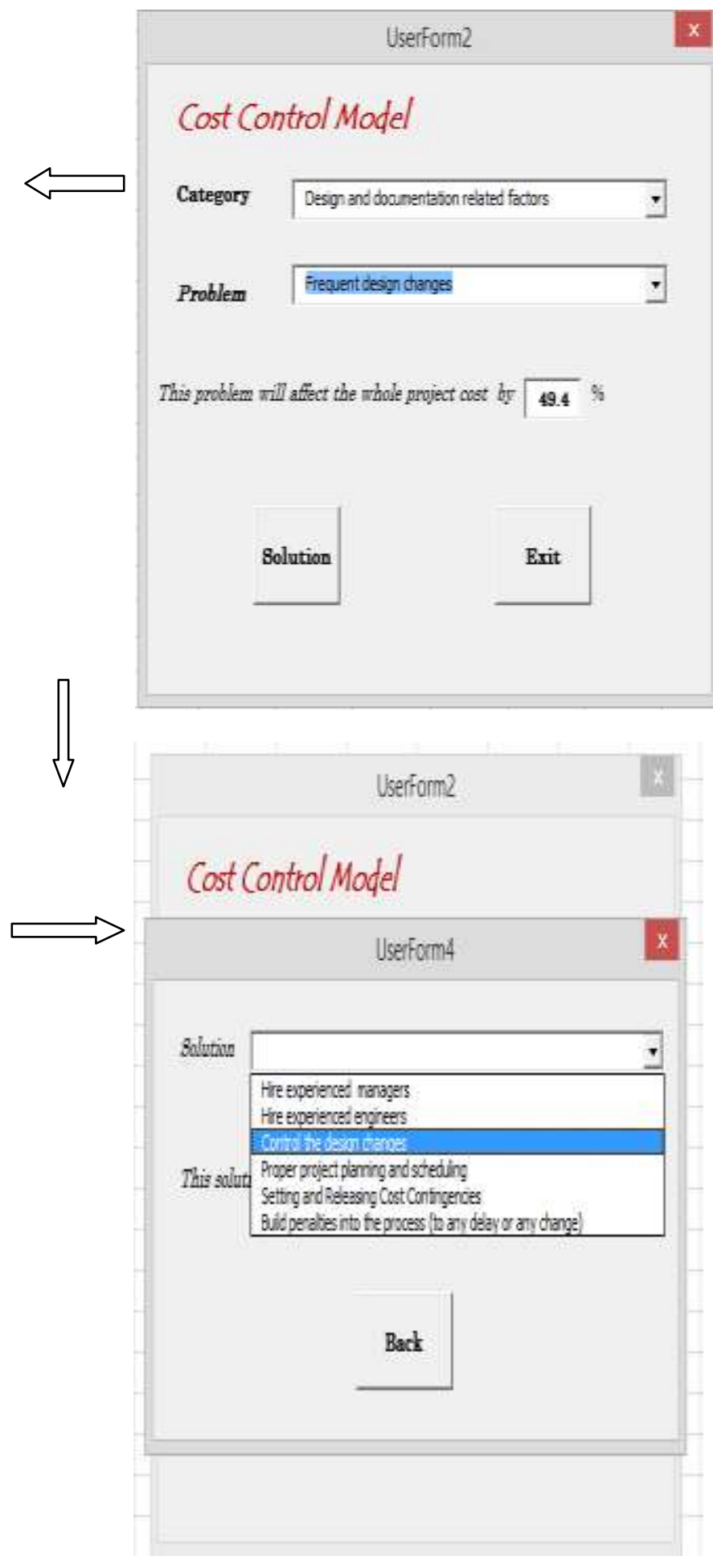

\section{CASE STUDY}

A case study was done according to one of the recent projects to examine the analysis, one of the project managers was asked to check our analysis according to a certain project he chooses.

The project manager has chosen "Dar masr" project in 6th of October city. The project is $75 \%$ completed. It is a real
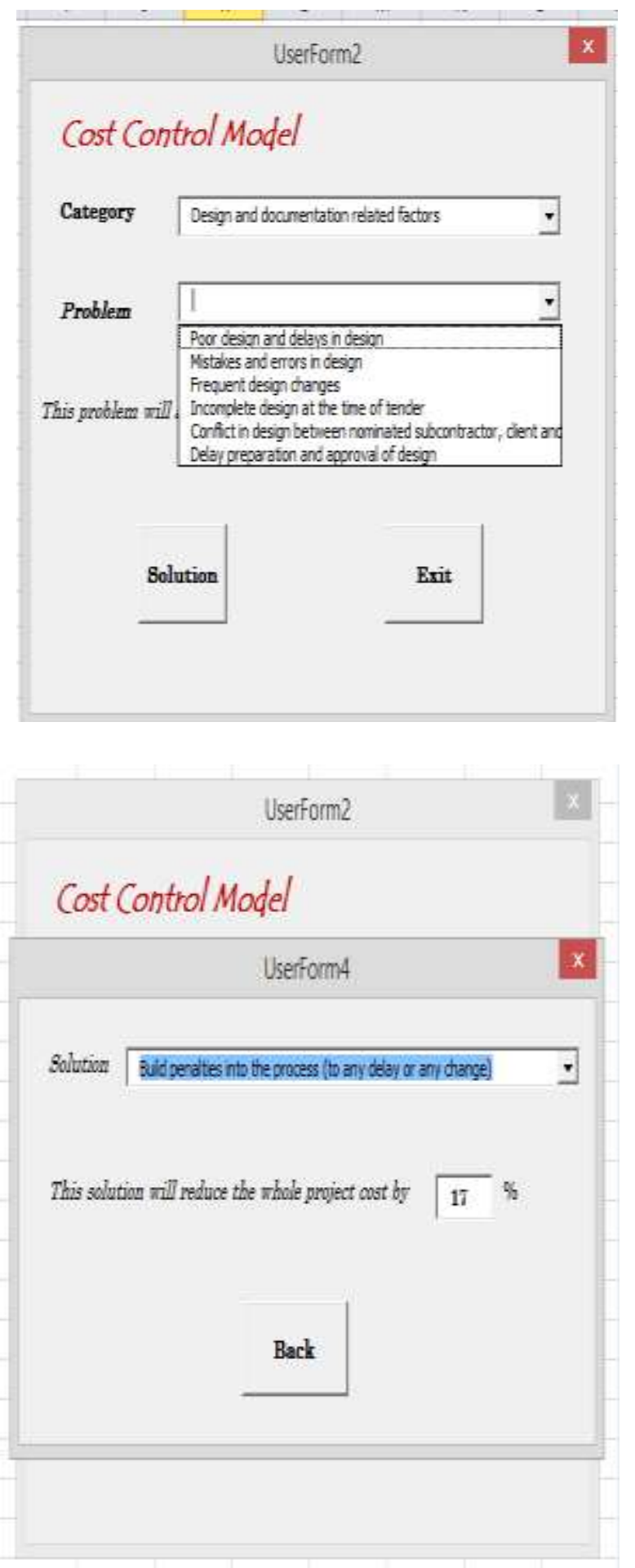

estate project which is $5000 \mathrm{~m} 2$ wide. It consists of 64 building each is $500 \mathrm{~m} 2$.

" Due to the fluctuation of price of materials, the inflation of material prices and the currency instability, the project till now has faced a $55 \%$ cost overrun, we are trying to minimize the expenses as possible to make profit" said the project manager. 
As per the factors causing cost overrun, the project manager has reported a $5 \%$ decrease or increase in most of the factors, but concerning their solutions, there was a very small variance between the percentages we got from our analysis and the percentages he reported.

\section{CONCLUSION}

The cost control and management of real estate construction is a systematic project. Its success depends on all participators dedication. This paper is supposed to exert certain effect on Egypt's real estate construction, with the hope of benefiting the cost control and management of real estate construction in future.

As we have 8 categories these were the top 8 factors causing cost overrun : fluctuation of price of materials causes overrun by $50.48 \%$ and its top solution was to study the market which will help to minimize the whole project cost by $34 \%$, shortage of site labors causes overrun by $42.58 \%$ and its top solution was effective site management and supervision which will help to minimize the whole project cost by $34 \%$, transportation delays causes overrun by $31.9 \%$ and its top solution was risk identification which will help to minimize the whole project cost by $26 \%$, change in scope of the project causes overrun by $49.1 \%$ and its top solutions were proper project planning and scheduling, which will help to minimize the whole project cost by $26 \%$, control the design changes ,effective site management and supervision and proper emphasis on past experience, each will help to minimize the whole project cost by $13 \%$,financial difficulties faced by contractors causes overrun by $48.4 \%$ and its top solutions were the use of the earned value method ,proper cost estimation at the beginning of the project, cash flow equation and build and perfect cost control system and implement a whole process control over cost each will help to minimize the whole project cost by $17 \%$, Lack of communication between parties causes overrun by $40.3 \%$ and its top solution coordination between all parties, frequent meetings which will help to minimize the whole project cost by $42 \%$, Lack of experience causes overrun by $48.61 \%$ and its top solutions were to hire experienced managers and frequent monitoring of the site each will help to minimize the whole project cost by $15 \%$, frequent design changes causes overrun by $49.4 \%$ and its top solutions were to hire experienced engineers, proper project planning and scheduling, setting and releasing cost contingencies and to build penalties into the process ( to any delay or any change) each will help to minimize the whole project cost by $17 \%$.

The second validation method used was the case study which was done on "Dar masr "project which is a real estate project which is $75 \%$ completed. The project has faced $55 \%$ cost overrun till now due to the fluctuation of price of materials, currency instability and the inflation of price of materials. Dar masr project manager has reported that decrease or increase in most of the factors causing cost overrun by $5 \%$ but concerning the solutions part there was a very small variance between the percentages we got from our analysis and the percentages he reported.
Based on the final percentages, the model was simulated. The model is visual basic programming language integrated in excel sheet, it is a programming tool used to simplify the results for 'the user. It was designed to be a guide for all parties involved in the construction field, the model is user friendly and can be edited easily for any future modification. Also, we recommend to use this analysis and model for any construction project and not to be limited to real estate projects.

\section{ACKNOWLEDGMENT}

I would like to express my deepest gratitude to all my family members ,I wouldn't have achieved anything without their encouragement and caring.

Also, I am grateful to my supervisor DR. Ayman Nassar expertise, understanding, generous guidance and support who guided me beginning from my graduate education and made it possible for me to work on a topic that was of great interest to me. It was a pleasure working with him.

\section{REFERENCES}

[1]. Elchaig, T., Boussabinaine A., \& Ballal T.. Critical determinants of construction tendering costs.(2005)

[2]. Hartley, J. R., \& Okamoto, S. . Concurrent engineering: Shortening lead times, raising quality.(1997)

[3]. Premalal, Mudalige, \& Malkanthi. . Study of Cost Control Techniques Used in Construction Industry.(2016) 